\title{
Acúmulo de solutos orgânicos em mudas de Ceiba glaziovii (Kutze) Kum. em resposta à seca intermitente
}

\author{
Organic compounds accumulation in Ceiba glaziovii (Kutze) Kum. seedlings in response to \\ intermittent drought
}

\author{
J. L. Santos Júnior; M. F. C. Oliveira; E. C. Silva* \\ Laboratório de Fisiologia e Ecofisiologia Vegetal, Universidade Federal de Sergipe, 49100000, São Cristóvão-SE, \\ Brasil
}

*elizaciriaco@gmail.com

(Recebido em 30 de setembro de 2019; aceito em 23 de janeiro de 2020)

\begin{abstract}
Ceiba glaziovii (Kuntze) K. é uma espécie ocorrente na Caatinga de importância econômica e ecológica. Contudo, o conhecimento da sua fisiologia em resposta à períodos de seca, na fase inicial do desenvolvimento, não são bem conhecidas. $O$ presente trabalho objetivou avaliar o teor relativo de água das folhas e o acúmulo de solutos orgânicos osmoticamente ativos em mudas de Ceiba glaziovii submetidas à seca intermitente. Para tal, mudas de um mês de idade de C. glaziovii foram submetidas à seca intermitente por ciclos de suspensão da irrigação [rega diária (C), irrigação a cada sete dias (E7), suspensão de rega até sinais de murcha como estresse severo (ES) e reirrigadas (RE), verificando a recuperação após 72 horas]. Avaliou-se a altura das plantas, o diâmetro do caule, teor relativo de água nas folhas, a concentração de prolina livre (PL), carboidratos (CS) e proteínas (PS) nas folhas e raízes. A seca intermitente exerceu pouco efeito sobre o TRA das mudas de C. glaziovii, porém afetou negativamente o crescimento delas. Não houve acúmulo de CS nas folhas, porém houve grande variação na concentração de PL e PS. Nas raízes das plantas E7 houve acúmulo significativo de CS, PL e PS, evidenciando o papel desses compostos no ajustamento osmótico no sistema radicular. A Ceiba glaziovii consegue manter valores adequados de água nos tecidos em situação de seca intermitente, durante o período inicial do desenvolvimento. A prolina se acumula nas folhas e raízes em resposta ao déficit hídrico moderado, sugerindo um papel importante para a sobrevivência da espécie.
\end{abstract}

Palavras-chave: déficit hídrico, prolina livre, barriguda.

Ceiba glaziovii (Kuntze) K. is an economically and ecologically important species occurring in Caatinga. However, information about its physiological responses to drought during initial seedling phase are nonexistent. The present work aimed to evaluate the leaves relative water content, and the accumulation of osmotically active organic solutes in Ceiba glaziovii seedlings submitted to intermittent drought. Thus, one month old C. glaziovii seedlings were subjected to intermittent drought by irrigation suspension cycles [control with daily watering (C), irrigation every seven days (E7), watering suspension until signs of wilting as severe stress (ES) e re-watered (RE), checking recovery after $72 \mathrm{~h}]$. Height, stem diameter, relative water content (TRA), free proline concentration (PL), carbohydrates (CS) and protein (PS) in leaves and roots were evaluated. The intermittent drought had little effect on TRA of $C$. glaziovii seedlings, but negatively affected growth. There was no accumulation of CS in the leaves, but a great variation in PL and PS content were observed. In the roots of E7 plants there was significant accumulation of CS, PL and PS, indicating the role of these compounds in the osmotic adjustment in the root system. Ceiba glaziovii maintains adequate tissue water values in intermittent drought conditions during its initial development phase. Proline accumulates in leaves and roots in response to moderate water deficit, suggesting an important role for species survival.

Keywords: water deficit, free proline, barriguda.

\section{INTRODUÇÃO}

As florestas tropicais sazonalmente secas (FTSS) se recuperam de forma mais lenta após eventos de seca prolongada do que as florestas tropicais úmidas [1]. Com o aumento da temperatura frente às mudanças climáticas globais estima-se que os eventos de seca se prolonguem e se tornem mais frequentes em ambientes secos, como as FTSS, tornando-se um fator importante e determinante na distribuição das espécies vegetais e nos processos ecossistêmicos [1 - 4]. Dessa forma, mesmo as espécies vegetais adaptadas a tais condições irão sofrer com esse cenário [3, 5 - 9]. 
A compreensão dos mecanismos utilizados por espécies que habitam em FTSS torna-se uma ferramenta importante, tanto do ponto de vista fisiológico como do ponto de vista ecológico, fornecendo informações relevantes para a utilização dessas espécies em programas de reflorestamento de áreas degradadas, como também para o entendimento da dinâmica da espécie em seu ambiente natural $[3,6,8,10,11]$

A seca afeta diversos processos vitais nas plantas, que são traduzidas em mudanças nos padrões de crescimento e de desenvolvimento $[5,10]$. Em parte, isso ocorre em virtude da redução da pressão de turgescência celular, inibindo a atividade fotossintética por limitações estomáticas (fechamento dos estômatos) e não estomáticas (limitações enzimáticas) [5, 6], além de reduzir o transporte de minerais e fotoassimilados necessários para o metabolismo vegetal, consequentemente, causando um decréscimo na fixação de carbono e produção de biomassa seca $[5,6]$. Em casos extremos, esse quadro pode levar a distúrbios sérios e até mesmo a morte [3, 5 $10]$.

Por outro lado, eventos de seca intermitente podem promover respostas positivas através de mudanças bioquímicas, estruturais e funcionais, capacitando as plantas a sobreviverem sob privação hídrica $[4,5,7,9]$. Para algumas espécies vegetais, uma maior disponibilidade de água não induz, necessariamente, em um melhor desempenho durante a fase inicial do desenvolvimento [10]. Assim, as respostas dos vegetais aos períodos de seca irão depender, entre outros fatores, da fase do desenvolvimento da planta, da intensidade e da duração dos períodos de seca [12]. Dessa forma, é de se esperar que as plantas que cresçam em ambientes sazonalmente secos apresentem uma série de estratégias de tolerância para evitar a desidratação dos seus tecidos, permitindo uma maior captação da água disponível no solo, favorecendo assim o crescimento e o desenvolvimento $[8,10]$.

O ajuste osmótico é uma das estratégias que contribuem para a sobrevivência das plantas em ambientes sazonalmente secos $[5,6,13]$. Isso se dá pelo acúmulo de compostos orgânicos osmoticamente ativos como os carboidratos e proteínas solúveis, aminoácidos, prolina, compostos quaternários de amônia como a betaína e a glicina-betaína, entre outras substâncias, que tem função osmorreguladora e protetora $[5,6,13]$. Associados a outras estratégias, esses compostos podem conferir tolerância à seca, ou por promover o ajustamento osmótico, retendo água dentro da célula e mantendo o seu influxo, ou por proteger as biomembranas e macromoléculas durante a desidratação $[3,5,13,14]$. Geralmente, à medida que a disponibilidade de água no solo diminui, alguns destes solutos se acumulam nas células [5], favorecendo o influxo de água, e ajuda na manutenção do metabolismo e do crescimento vegetal $[4,5,13]$.

Ceiba glaziovii (Kuntze) K. Schum é uma espécie endêmica do nordeste brasileiro que possui como uma de suas características adaptativas e taxonômicas a grande capacidade de retenção hídrica no caule. Apresenta canais de mucilagem por toda a sua estrutura, desde as raízes até as folhas $[15,16]$. É uma espécie que apresenta importância econômica, farmacológica e ecológica, sendo utilizada também para a recuperação de áreas degradadas [15, 17 - 20]. Embora essas características na arquitetura e anatomia da espécie, bem como seus diversos usos, sejam conhecidas, estudos sobre sua fisiologia, especialmente os mecanismos utilizados para sobreviver a períodos de seca durante a fase inicial do crescimento, são inexistentes.

Diante da importância da espécie e da ausência de estudos sobre os efeitos da seca na fase inicial do crescimento de $C$. glaziovii, nos perguntamos se as mudas poderiam acumular compostos orgânicos osmoticamente ativos em resposta ao déficit hídrico, favorecendo seu estabelecimento e permanência em florestas sazonalmente secas. Dessa forma, o presente trabalho objetivou avaliar o teor relativo de água das folhas e o acúmulo de solutos orgânicos osmoticamente ativos em mudas de Ceiba glaziovii submetidas à seca intermitente. Verificando, assim, a plasticidade fisiológica desses compostos para uma melhor compreensão dos mecanismos utilizados pela espécie em situação de déficit hídrico no solo para sobreviver e se estabelecer em ambientes sazonalmente secos. 


\section{MATERIAL E MÉTODOS}

A pesquisa foi realizada na estufa agrícola e no Laboratório de Fisiologia e Ecofisiologia Vegetal da Universidade Federal de Sergipe (UFS). As mudas foram obtidas de sementes coletadas em Paripiranga/BA, região situada no Semiárido (1041'00"S; 3751'00"O). Elas foram colocadas para germinar em bandeja contendo areia lavada e, após a emergência, foram transplantadas para sacos de polietileno com capacidade para $4,5 \mathrm{~kg}$, contendo como substrato uma mistura de terra vegetal, areia lavada e esterco bovino, na proporção 3:1:1 (v/v), com adição de $50 \mathrm{~g}$ de superfosfato simples. As mudas foram regadas próximas à capacidade de campo (20\%) durante 30 dias. Após essa etapa, deu-se início a diferenciação dos tratamentos hídricos. O experimento foi conduzido por 73 dias.

A temperatura média durante esse período foi de $29,6{ }^{\circ} \mathrm{C}$, variando de $25,9{ }^{\circ} \mathrm{C}$ a $31,3{ }^{\circ} \mathrm{C}$. A umidade relativa do ar média foi de $64,8 \%$, variando de $49,4 \%$ a $75,3 \%$. Nos horários da coleta a temperatura variou de $27,5^{\circ} \mathrm{C}$ a $39,2^{\circ} \mathrm{C}$ e a umidade relativa do ar variou de $47,3 \%$ a $62,3 \%$ (Figura $1)$.

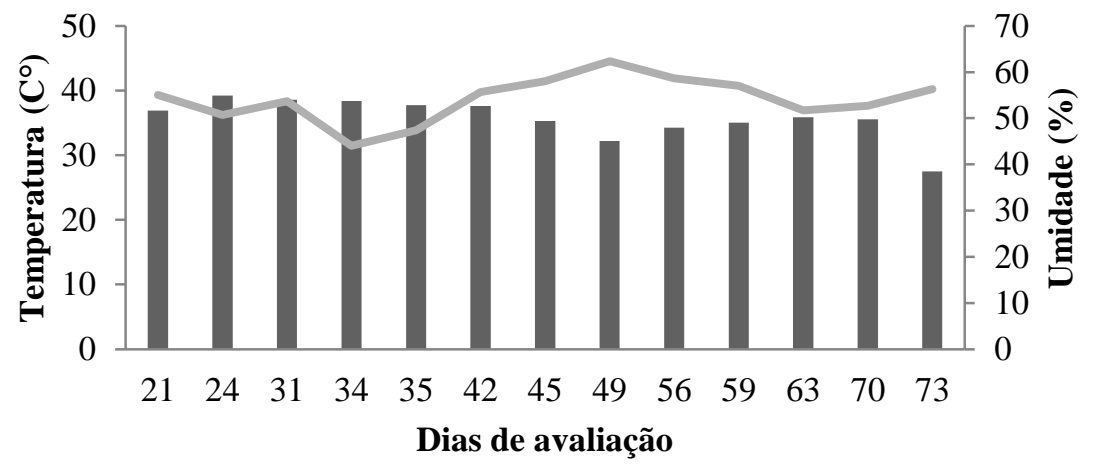

Temperatura $\left(\mathrm{C}^{\circ}\right) \longrightarrow$ Umidade $(\%)$

Figura 1: Umidade relativo do ar (\%) e temperatura $\left({ }^{\circ} \mathrm{C}\right)$ no horário das coletas das folhas de mudas de Ceiba glaziovii submetidas à seca intermitente.

O desenho experimental foi inteiramente casualizado com quatro tratamentos hídricos [rega diária (C), intervalos entre as regas de sete dias (E7), suspensão da rega até que as folhas apresentassem sinais de murcha como estresse severo (ES), e reirrigadas (RE) verificando a recuperação após 72h], com cinco repetições por tratamento.

As mudas foram avaliadas fisiologicamente quanto ao teor relativo de água nas folhas (TRA), e a concentração de solutos orgânicos em folhas e raízes. Foram selecionadas folhas maduras e expandidas localizadas no terço superior das mudas, as quais foram coletadas ao meio-dia, horário de maior demanda evaporativa.

O teor relativo de água foliar (TRA) foi avaliado seguindo a metodologia descrita por Cairo (1995) [21], utilizando o peso da matéria fresca (PMF), túrgida (PMT) e seca (PMS) de seis discos foliares do limbo sem a nervura central. O TRA das mudas controle e E7 foram determinados quinzenalmente, enquanto que no tratamento ES, o TRA foi determinado quando as folhas apresentavam sinais de murcha, variando de 7 a 14 dias. A recuperação (RE) foi avaliada 72 horas após a reirrigação. O TRA foi expresso em porcentagem (\%), utilizando a seguinte equação descrita em Weatherley et al. (1950) [22]:

$$
T R A=P M F-P M S / P M T-P M S \times 100
$$

Para uma maior compreensão da influência da manutenção da hidratação dos tecidos (TRA) sobre o crescimento das plantas, também foram realizadas medidas da altura e do diâmetro do caule em intervalos quinzenais, iniciando no sétimo dia após diferenciação dos tratamentos. Para tanto, foram utilizados régua e paquímetro digital da marca Digimess, respectivamente, medindo sempre no mesmo local, previamente marcado.

Para as análises bioquímicas foi utilizado cerca de $0,5 \mathrm{~g}$ do limbo foliar fresco sem a nervura central e $1 \mathrm{~g}$ para as raízes. O material vegetal foi macerado em almofariz contendo $5 \mathrm{~mL}$ de solução tampão de fosfato monobásico $0,1 \mathrm{M}, \mathrm{pH} 7$ contendo EDTA a $0,01 \mathrm{M}$, filtrado em malha de nylon, transferidos para tubos, centrifugados a $4.000 \mathrm{x}$ g por 30 minutos para tecido foliar e 15 minutos 
para amostras de raízes. O sobrenadante foi acondicionado em tubos eppendorfs de $2 \mathrm{~mL}$ e congelados a $-18^{\circ} \mathrm{C}$.

A determinação da concentração de carboidratos solúveis totais foi realizada colorimetricamente $(490 \mathrm{~nm})$ em uma alíquota de $0,5 \mathrm{~mL}$ do extrato bruto, pelo método do fenol-ácido sulfúrico, utilizando a D-(+)-glucose como padrão [23]. A prolina livre foi determinada colorimetricamente a $520 \mathrm{~nm}$, em uma alíquota de $1 \mathrm{~mL}$ do extrato, utilizando a ninhidrina como reagente específico e a prolina pura como padrão [24]. As proteínas solúveis foram determinadas colorimetricamente $(595 \mathrm{~nm})$ pelo método de ligação ao corante, em uma alíquota de $2 \mathrm{~mL}$ do extrato, utilizando a albumina de soro bovino pura como padrão [25].

A umidade do solo foi medida antes da reirrigação das plantas estressadas e em intervalos de 1 hora até os vasos retornarem à capacidade de campo ( $20 \%$ da umidade volumétrica do solo). Utilizou-se um medidor de umidade do solo Hidrofarm modelo HFM2010 da Falker.

Para avaliar a plasticidade fisiológica das variáveis estudadas, foi utilizado o índice de plasticidade fenotípica ( 0 a 1 ), calculado como sendo a diferença entre o maior e o menor valor médio entre os tratamentos, dividido pelo maior valor médio. Quanto maior o valor do IP maior a plasticidade da variável analisada $[9,26]$.

Os dados fisiológicos foram submetidos ao teste de normalidade Shapiro-Wilk. Os dados com distribuição normal foram submetidos à análise de variância (ANOVA) duplo fator e as médias foram comparadas pelo teste de Tukey $(\mathrm{P}<0,05)$. Os dados não paramétricos (carboidratos solúveis totais radiculares, proteínas totais foliares e radiculares e prolina livre foliar) foram submetidos à análise pelo teste de Kruskal-Wallis e as médias comparadas pelo teste de Mann-Whitney a 5\% de probabilidade utilizando o software Past versão 3.21. Regressão linear foi utilizada para os parâmetros de crescimento ao longo do tempo. Os gráficos foram confeccionados utilizando o programa SigmaPlot versão 12.0 e Excel (Office 365).

\section{RESULTADOS E DISCUSSÃO}

A rega intermitente promoveu a redução da umidade do solo, o que ocorreu tanto pela demanda evaporativa como pelo consumo de água pelas plantas. A umidade do solo das plantas controle, antes da irrigação, variou de $13,74 \%$ a $19,98 \%$ ao longo do período experimental. Para as plantas cultivadas com intervalo de sete dias entre as regas (E7), a umidade do solo variou de $6,32 \%$ a $12,34 \%$, e para as plantas com suspensão da irrigação até que as mesmas apresentassem sinais de murcha foliar (ES) os valores variaram de 7,56\% a 9,64\%, demonstrando claramente a privação hídrica que as plântulas estressadas estavam sofrendo (Tabela 1). A baixa disponibilidade de água no solo tem sido apontada como um dos principais fatores de estresse para as plantas, afetando a distribuição e sobrevivência das espécies em ambientes semiáridos [2, 3, 5, 6].

Tabela 1: Percentagem de umidade do solo (\%) antes da reirrigação das mudas de Ceiba glaziovii submetidas à seca intermitente. $C$ - controle, com rega diária; E7, regas em intervalos de sete dias, ESintervalos de suspensão de regas até que as mesmas apresentassem sinais de murcha nas folhas. Média \pm desvio-padrão de cinco repetições.

\begin{tabular}{cccc}
\hline Dias após diferenciação* & \multicolumn{3}{c}{ Tratamentos } \\
\cline { 2 - 4 } & Controle & E7 & ES \\
\hline $7 / 7$ & $19.98 \pm 5,39$ & $12,34 \pm 3,06$ & $9,52 \pm 1,67$ \\
$21 / 21$ & $15,67 \pm 3,32$ & $10,60 \pm 2,65$ & $9,32 \pm 2,37$ \\
$35 / 31$ & $16,80 \pm 5,90$ & $9,58 \pm 3,40$ & $9,64 \pm 2,82$ \\
$49 / 42$ & $13,28 \pm 4,27$ & $9,34 \pm 2,03$ & $9,14 \pm 2,10$ \\
$63 / 56$ & $13,74 \pm 1,90$ & $10,00 \pm 2,8$ & $8,74 \pm 0,87$ \\
$70 / 70$ & $14,12 \pm 2,52$ & $6,32 \pm 1,30$ & $7,56 \pm 1,36$ \\
\hline MÉDIA & 15,59 & 9,69 & 8,98 \\
\hline
\end{tabular}

* Os dados na coluna época após a barra simboliza os dias de avaliação das mudas sob estresse severo (ES), correspondendo aos dias em que as mesmas apresentaram sintomas de murcha nas folhas. 
Para as plantas reirrigadas (RE), a umidade do solo foi restaurada até atingirem a capacidade de campo, ou seja, $20 \%$ da umidade volumétrica do solo. O tempo de suspensão da irrigação nas plantas ES capaz de provocar sintomas de murcha nas folhas variou de 7 a 14 dias durante o período experimental.

A seca intermitente exerceu pouco efeito sobre o teor relativo de água das folhas (TRA) das mudas de $C$. glaziovii durante o período experimental, não havendo, de maneira geral, diferenças significativas entre os tratamentos hídricos utilizados. Esses resultados indicam que as mudas de C. glaziovii sob seca intermitente conseguem manter os valores de TRA das folhas próximo ao das plantas controle, regadas diariamente (Tabela 2).

Por outro lado, percebeu-se uma redução gradual nos valores de TRA das folhas ao longo do tempo, independente do tratamento hídrico, o que demonstra um maior consumo e perda de água pelas plantas à medida que as mesmas crescem. Isso pode ser observado também com o decréscimo da umidade do solo nos diferentes tratamentos no decorrer do tempo (Tabela 1), demonstrando o maior consumo hídrico pelas plantas.

Dessa maneira, a redução dos valores de TRA de cerca de $80 \%$ para cerca de $60 \%$ nas plantas controle (C) evidenciou uma resposta ao crescimento, com aumento da demanda hídrica pelas mesmas $[5,6,12,27]$. Em contrapartida, as plantas estressadas reduziram (E7) ou paralisaram (ES) o crescimento ao longo do tempo devido ao prolongamento do déficit hídrico e os intervalos da reirrigação hídrica, sendo maior nas ES, o que provocou um menor crescimento ao longo do tempo (Figura 2). Dessa forma, as plantas estressadas conseguiram manter valores adequados de TRA nas folhas em detrimento do crescimento. Isso reflete uma menor aquisição de carbono pelas plantas, mas, ao mesmo tempo, garante a manutenção do metabolismo com menos gasto metabólico para a formação de esqueleto de carbono que resulte em aumento de massa seca. Dessa forma, embora o TRA não tenha sido afetado, os resultados sugerem que as mudas de $C$. glaziovii devem apresentar limitações estomáticas em função do crescimento mais lento.

Após a reidratação as plantas RE não demonstraram um aumento significativo dos valores de TRA sobre as plantas ES. A variação que ocorreu no TRA pode estar relacionada ao tempo de avaliação (72 horas após a reirrigação), o que pode ter promovido uma maior perda de água por transpiração após a reidratação, sendo observada uma recuperação significativa $(\mathrm{P}>0,05)$ apenas na penúltima coleta. A hidratação dos tecidos, mesmo em condições de seca, possibilita a manutenção das atividades do metabolismo energético, bem como garante processos de divisão e alongamento celulares [5, 14].

Tabela 2: Teor relativo de água (TRA) foliar (\%) de mudas de Ceiba glaziovii submetidas à seca intermitente. $C$ - controle, com rega diária; E7, regas em intervalos de sete dias, ES - intervalos de suspensão de regas até que as mesmas apresentassem sinais de murcha nas folhas e RE - 72 horas após reirrigação.

\begin{tabular}{ccccc}
\hline Dias de & \multicolumn{4}{c}{ Tratamentos } \\
\cline { 2 - 5 } avaliação** & Controle $(\%)$ & E7 $(\%)$ & ES $(\%)$ & RE $(\%)$ \\
\hline $7 / 7$ & $80,42 \mathrm{aA}$ & $83,86 \mathrm{aA}$ & $81,73 \mathrm{aA}$ & $86,99 \mathrm{aA}$ \\
$21 / 21$ & $73,28 \mathrm{abAB}$ & $83,76 \mathrm{aA}$ & $76,61 \mathrm{abA}$ & $64,10 \mathrm{bBC}$ \\
$35 / 31$ & $62,72 \mathrm{bB}$ & $63,37 \mathrm{bB}$ & $73,92 \mathrm{abAB}$ & $83,04 \mathrm{aA}$ \\
$49 / 42$ & $70,39 \mathrm{aAB}$ & $68,54 \mathrm{aAB}$ & $68,21 \mathrm{aBC}$ & $78,30 \mathrm{aAB}$ \\
$63 / 56$ & $65,93 \mathrm{bB}$ & $63,54 \mathrm{bB}$ & $61,26 \mathrm{bBC}$ & $80,04 \mathrm{aAB}$ \\
$70 / 70$ & $62,70 \mathrm{aB}$ & $62,07 \mathrm{aB}$ & $56,88 \mathrm{aC}$ & $56,59 \mathrm{aC}$ \\
\hline
\end{tabular}

* Médias seguida de mesma letra, minúscula, entre os tratamentos hídricos e maiúsculas entre as épocas de avaliação, não diferem significantemente pelo teste de Tukey $(P<0,05)$.

** Os dados na coluna época após a barra simboliza os dias de avaliação das mudas sob estresse severo (ES), correspondendo aos dias em que as mesmas apresentaram sintomas de murcha nas folhas.

Observou-se resposta linear, conforme equação de regressão, para altura e diâmetro de caule de C. glaziovii (Figura 2). Os parâmetros de crescimento avaliados evidenciaram que, apesar da $C$. glaziovii conseguir manter seus tecidos hidratados sob escassez hídrica, a seca intermitente afeta negativamente o crescimento no estágio inicial de desenvolvimento, causando reduções significativas na altura das plantas e no diâmetro do caule (Figura 2). A seca intermitente tanto 
pode reduzir o crescimento [28] como promovê-lo [10], dependendo da espécie e suas respostas para essa condição $[5,6]$.

Embora a transpiração foliar não tenha sido avaliada no presente trabalho, é possível que a espécie utilize o controle desse mecanismo através do fechamento estomático para manter a água nos tecidos. Dessa forma, a manutenção do TRA e a redução do crescimento das mudas de $C$. glaziovii poderiam ser explicados [5]. O fechamento dos estômatos é considerado como uma das primeiras linhas de defesa para evitar a desidratação como consequência da seca sobre as plantas $[5,6,12]$.

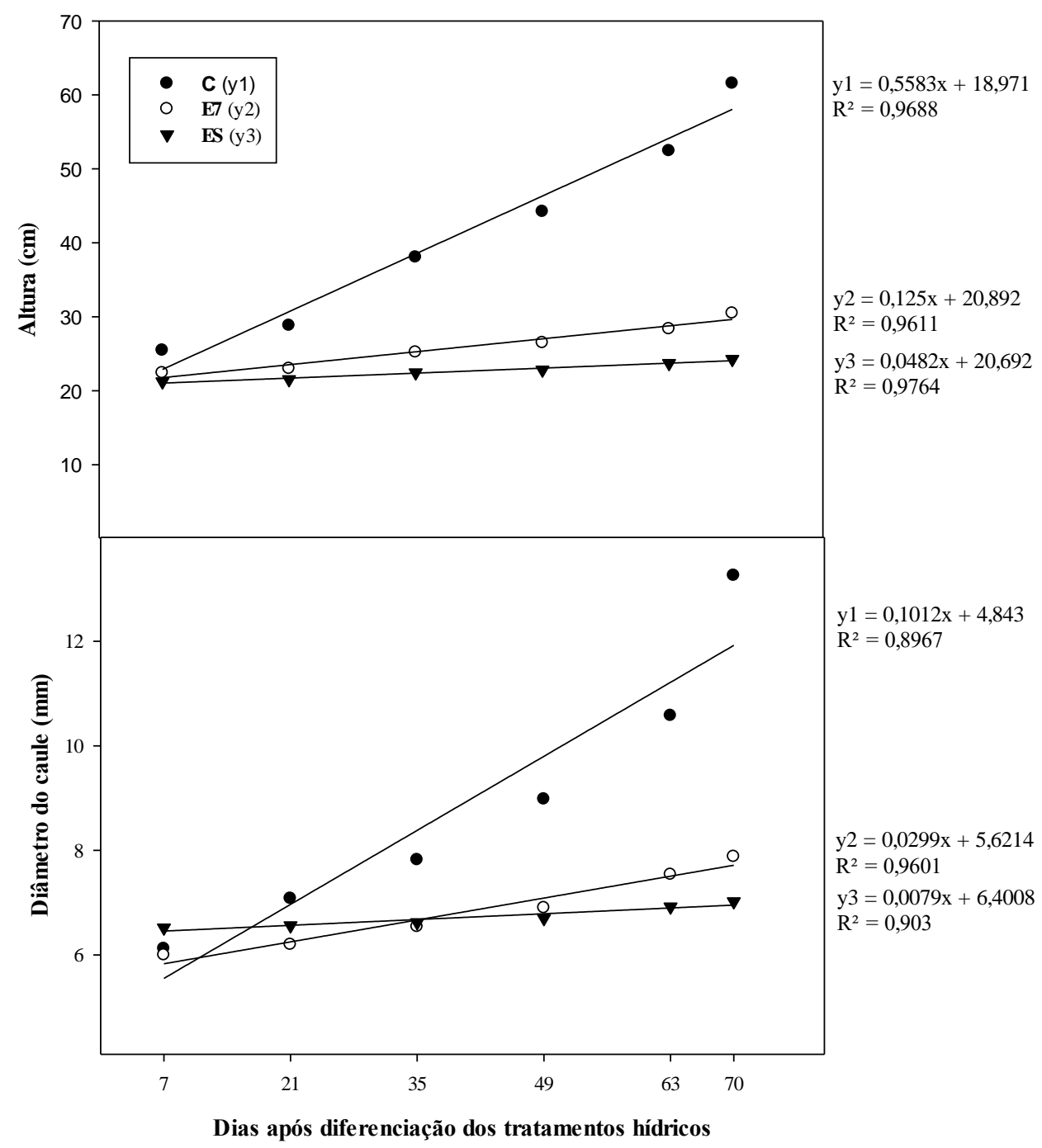

Figure 2: Altura e diâmetro do caule de mudas de Ceiba glaziovii submetidas à seca intermitente. $C$ controle, com rega diária; E7, regas em intervalos de sete dias, ES - intervalos de suspensão de regas até que as mesmas apresentassem sinais de murcha nas folhas.

O acúmulo de compostos orgânicos de baixo peso molecular, também chamado de solutos compatíveis, é um mecanismo importante para a manutenção da hidratação dos tecidos $[5,13]$. Esses solutos podem se acumular por síntese ou degradação de outros compostos orgânicos [3]. Carboidratos, proteínas e prolina livre, ajudam a diminuir o potencial osmótico, permitindo maior absorção de água pela célula, favorecendo um potencial de pressão adequado, reduzindo danos causados pela escassez hídrica através da manutenção de água no interior da célula $[3,5,12,13]$. A redução nos níveis de proteínas solúveis, por exemplo, é um dos indicadores da senescência nas plantas [29].

No entanto, as mudas de $C$. glaziovii não acumularam carboidratos solúveis em suas folhas em resposta à seca intermitente, apresentando uma grande variação na concentração de prolina livre 
nas folhas e reduções esporádicas nos níveis de proteínas solúveis (Tabela 3). Nas plantas mais estressadas (ES) foi possível observar acúmulo de prolina livre no período inicial do estresse (após sete dias de tratamento), e aos 70 dias (Tabela 3). De forma contrária, houve reduções na concentração de proteínas solúveis aos 7 e 63 dias. Dessa forma, esse comportamento não pode ser considerado como um padrão de resposta ao déficit hídrico, embora contribua para o ajustamento das plantas as condições de estresse.

Tabela 3: Concentração de carboidratos solúveis totais, proteínas solúveis e prolina livre nas folhas de mudas de Ceiba glaziovii submetidas à seca intermitente. C- controle, com rega diária; E7, regas em intervalos de sete dias, ES - intervalos de suspensão de regas até que as mesmas apresentassem sinais de murcha nas folhas e RE - 72 horas após reirrigação.

\begin{tabular}{|c|c|c|c|c|}
\hline \multirow{3}{*}{ Dias de avaliaçãa*** } & \multicolumn{4}{|c|}{ Carboidratos solúveis $(\mu \mathrm{mol} / \mathrm{gMF})$} \\
\hline & \multicolumn{4}{|c|}{ Tratamentos hídricos } \\
\hline & Controle & E7 & ES & RE \\
\hline $07 / 07$ & $73,29 \mathrm{abB}$ & $50,42 \mathrm{bC}$ & $78,32 \mathrm{abA}$ & $105,01 \mathrm{aBC}$ \\
\hline $21 / 21$ & $160,01 \mathrm{aA}$ & $123,55 \mathrm{aC}$ & $124,61 \mathrm{aA}$ & $139,02 \mathrm{aC}$ \\
\hline $35 / 31$ & $121,93 \mathrm{aAB}$ & $86,61 \mathrm{aC}$ & $90,88 \mathrm{aA}$ & $91,86 \mathrm{aBC}$ \\
\hline $49 / 42$ & 173,69 abA & $202,68 \mathrm{aA}$ & $129,77 \mathrm{bA}$ & $200,97 \mathrm{aA}$ \\
\hline 63/56 & $116,10 \mathrm{abA}$ & $118,58 \mathrm{abBC}$ & $125,24 \mathrm{aA}$ & $67,23 \mathrm{bB}$ \\
\hline \multirow[t]{3}{*}{ 70/70 } & $144,46 \mathrm{aA}$ & $164,98 \mathrm{aAB}$ & $132,53 \mathrm{aA}$ & $130,88 \mathrm{aC}$ \\
\hline & \multicolumn{4}{|c|}{ Proteínas solúveis totais (mg/gMF) } \\
\hline & Controle & E7 & ES & $\mathbf{R E}$ \\
\hline $07 / 07$ & $14,80 \mathrm{aB}$ & $8,40 \mathrm{aB}$ & $3,94 \mathrm{bB}$ & $5,98 \mathrm{bB}$ \\
\hline $21 / 21$ & $16,41 \mathrm{aB}$ & $15,29 \mathrm{aBC}$ & $15,33 \mathrm{aA}$ & $16,45 \mathrm{aA}$ \\
\hline $35 / 31$ & $9,25 \mathrm{aA}$ & $11,80 \mathrm{aA}$ & $9,76 \mathrm{aB}$ & $7,32 \mathrm{aAB}$ \\
\hline $49 / 42$ & $9,16 \mathrm{aB}$ & $5,99 \mathrm{aB}$ & $10,85 \mathrm{aAB}$ & $11,99 \mathrm{aAB}$ \\
\hline $63 / 56$ & $24,47 \mathrm{aAB}$ & $20,51 \mathrm{aABC}$ & $5,19 \mathrm{bB}$ & $6,44 \mathrm{bB}$ \\
\hline \multirow[t]{3}{*}{$70 / 70$} & $4,66 \mathrm{cB}$ & $5,81 \mathrm{bcBC}$ & $8,99 \mathrm{aA}$ & $9,49 \mathrm{abAB}$ \\
\hline & \multicolumn{4}{|c|}{ Prolina livre $(\mu \mathrm{mol} / \mathrm{gMF})$} \\
\hline & Controle & E7 & ES & $\mathbf{R E}$ \\
\hline 07/07 & $2,37 \mathrm{bB}$ & $4,30 \mathrm{abBC}$ & $10,90 \mathrm{aABC}$ & $6,59 \mathrm{abB}$ \\
\hline $21 / 21$ & $6,66 \mathrm{aB}$ & $6,9 \mathrm{aBC}$ & $5,04 \mathrm{aB}$ & $6,97 \mathrm{aB}$ \\
\hline $35 / 31$ & $18,22 \mathrm{bA}$ & $23,63 \mathrm{abA}$ & $16,05 \mathrm{bcA}$ & $27,08 \mathrm{aA}$ \\
\hline $49 / 42$ & $6,87 \mathrm{aB}$ & $6,2 \mathrm{aB}$ & $8,4 \mathrm{aAB}$ & $7,2 \mathrm{aB}$ \\
\hline $63 / 56$ & $14,29 \mathrm{aAB}$ & $14,6 \mathrm{aBC}$ & $6,11 \mathrm{bBC}$ & $7,44 \mathrm{abB}$ \\
\hline $70 / 70$ & $4,85 \mathrm{bB}$ & $6,92 \mathrm{abBC}$ & $13,68 \mathrm{aABC}$ & $3,96 \mathrm{bB}$ \\
\hline
\end{tabular}

* Médias seguida de mesma letra, minúscula, entre os tratamentos hídricos e maiúsculas entre as épocas de avaliação, não diferem significantemente pelo teste de Tukey $(P<0,05)$ para carboidratos e pelo teste de Mann-Whitney $(P<0,05)$ para proteínas e prolina.

** Os dados na coluna época após a barra simboliza os dias de avaliação das mudas sob estresse severo (ES), correspondendo aos dias em que as mesmas apresentaram sintomas de murcha nas folhas.

Entre as épocas de avaliação houve grande variação para concentração de prolina e proteína nas folhas em todos os tratamentos hídricos. Em contrapartida, observou-se um acúmulo significativo de carboidratos nas folhas ao longo do tempo nas plantas controle, aumentando a concentração de forma crescente do período inicial até o final do período experimental. Avaliando as épocas para as plantas E7, houve um acúmulo significativo do período final em comparação ao período inicial. Já as plantas ES não tiveram um acúmulo significativo ao longo das épocas de avaliação. Como consequência, também não houve redução na concentração de carboidratos nas folhas das plantas $\mathrm{RE}$, comportamento esperado quando há acúmulo em resposta ao estresse e as plantas são reirrigadas, reduzindo a concentração por diluição [30]. 
À medida que as plântulas crescem e as folhas ficam maduras, estas se tornam mais ativas quanto à fotossíntese, tendo como produto deste processo a produção de carboidratos [3, 5]. Isso justifica os resultados encontrados no presente trabalho com relação ao aumento na concentração de carboidratos ao longo do tempo.

Ao contrário das folhas, as raízes das plantas estressadas (E7) apresentaram acúmulos significativos de carboidratos solúveis totais, proteínas solúveis e prolina livre em comparação aos demais tratamentos hídricos (Figura 3), evidenciando o papel desses compostos no ajustamento osmótico realizado no sistema radicular, o que garantiria o influxo de água do solo para a planta nestas condições $[3,5,6,10,31]$.

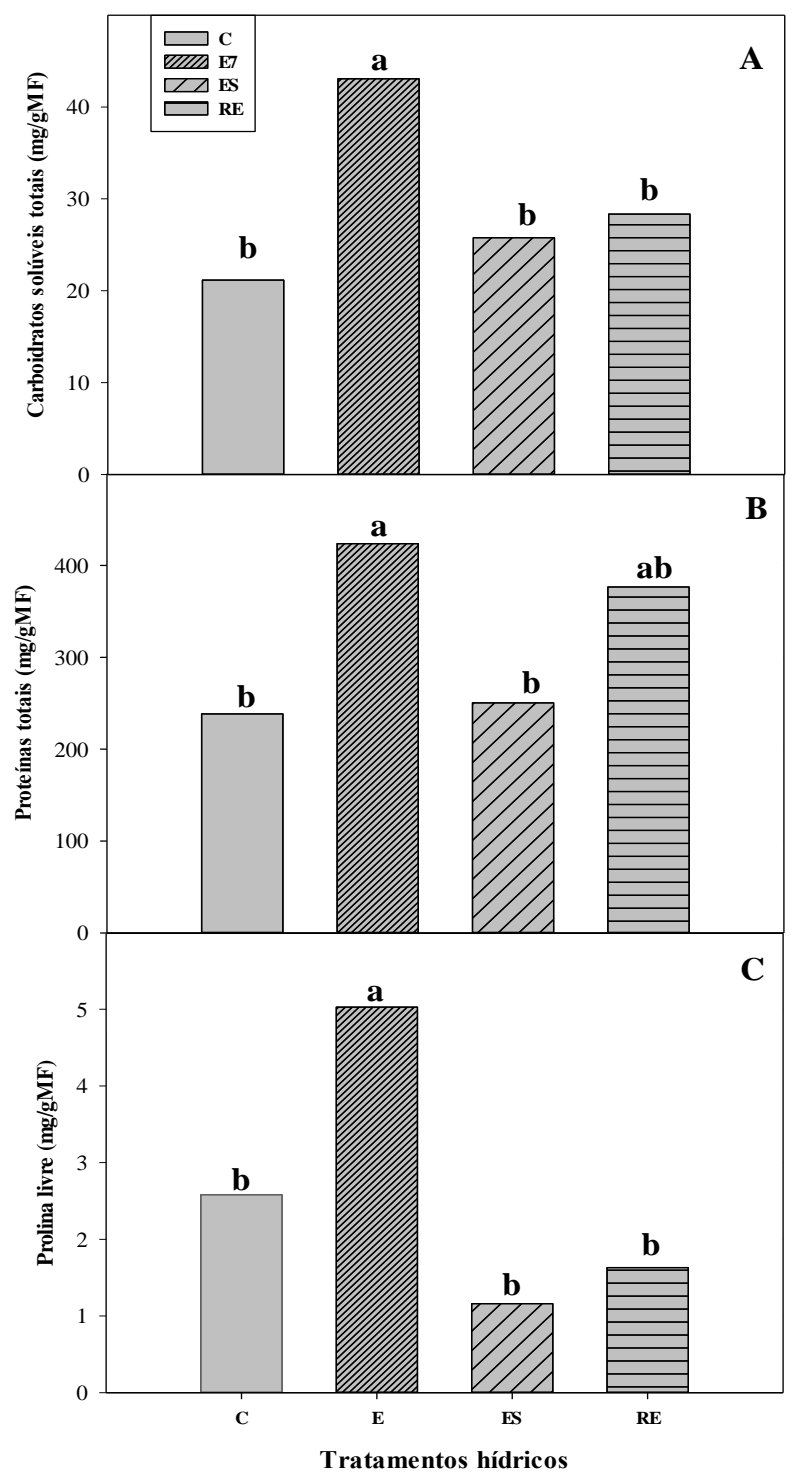

Figura 3: Concentração de carboidratos solúveis totais, proteínas totais e prolina livre nas raízes de mudas de Ceiba glaziovii submetidas à seca intermitente. $C$ - controle, com rega diária; E7, regas em intervalos de sete dias, ES - intervalos de suspensão de regas até que as mesmas apresentassem sinais de murcha nas folhas e RE - 72 horas após reirrigação. Letras iguais não diferem significantemente pelo teste de Tukey para carboidratos e prolina livre $(P<0,05)$ e pelo teste de Mann-Whitney $(P<0,05)$ para proteínas.

De maneira geral, os vegetais superiores acumulam algum tipo de composto orgânico compatível, de baixo peso molecular, em resposta ao estresse, seja por síntese ou por degradação. $\mathrm{O}$ aumento e a posterior degradação na concentração destes compostos desempenha um importante papel na adaptação das plantas a ambientes sazonalmente secos $[3,6,32]$. 
A prolina é considerada um osmólito muito importante nas plantas sob estresse, pois, além de colaborar com o ajustamento osmótico, apresenta papel importante na proteção contra a desnaturação enzimática e na remoção de espécies reativas de oxigênio, contribuindo para evitar o estresse oxidativo $[2,4,5,6]$. No entanto, nem sempre esse acúmulo ocorre nas folhas. Espécies endêmicas da caatinga como Maytenus rigida Mart. e Aspidosperma pyrifolium Mart. não apresentaram acúmulos significativos de prolina em suas folhas [32], utilizando-se de outras estratégias para sobreviver durante períodos de seca, corroborando com os resultados encontrados para a prolina livre foliar nesse trabalho.

O acúmulo de solutos nas plântulas submetidas a estresse moderado (E7) pode estar associado à fase de alarme do vegetal ao primeiro sinal da seca $[5,15,33]$ como uma medida protetiva, garantindo a manutenção da hidratação de seus tecidos [14, 15, 19]. Essa medida protetiva prepara a planta para condições de seca mais severa posteriormente. No entanto, quando as plantas atingiram um grau mais severo de estresse (ES), esses solutos foram reduzidos (ou degradados), o que leva a crer que a planta se utilize de outros mecanismos nesta condição mais severa de seca intermitente para sobreviver no ambiente. Apesar do ajustamento osmótico ser uma das estratégias adotadas pelas plantas para sobrepujarem as injúrias da seca, ela apresenta um custo energético elevado $[5,6,14]$. Por este motivo, outros mecanismos geralmente são acionados, como o controle estomático $[3,5,10]$.

Por ser endêmica do nordeste brasileiro, a C. glaziovii apresenta característica adaptativa para sobreviver em condições de seca, e uma delas é a presença de canais de mucilagem e um caule com grande capacidade de retenção hídrica devido ao seu parênquima aquífero [16, 19]. Embora a mucilagem não tenha sido avaliada no presente trabalho, a sua composição poderia justificar os resultados referente à concentração de carboidratos solúveis totais foliares, visto que não houve um acúmulo significativo dos carboidratos nas folhas das plântulas estressadas e nem uma redução significativa nas plantas reirrigadas de $C$. glaziovii. A mucilagem (hidrocolóides) é uma substância viscosa formada principalmente por heteropolissacarídeos ou polissacarídeos compostos por pentoses, ácidos e/ou neutros, substâncias fenólicas, proteínas e aminoácidos [26, 34, 33], que atua como reserva de carboidratos [34, 31]. A presença dessa mucilagem nas folhas é uma característica da família Malvaceae, que certamente colabora na tolerância à seca [35, 31], abrindo precedentes para trabalhos futuros. A presença de mucilagem nas folhas da C. glaziovii [15] em conjunto com o parênquima aquífero e a lâmina foliar hipoestomática $[15,16,36]$ presente na espécie podem estar auxiliando na manutenção dos valores do TRA, possibilitando tanto a retenção de água nos tecidos, como auxiliando na redução da transpiração e a ampliação da resistência contra altas temperaturas, contribuindo para a sobrevivência da espécie em ambientes semiáridos [35 - 38].

A matriz de correlação de Pearson mostrou uma relação significativa $(P<0,05)$ inversa entre a umidade do solo e o acúmulo de proteína e prolina livre nas folhas (Tabela 5), sugerindo que a redução da umidade do solo induz medidas osmoprotetivas nas folhas, aumentando a concentração destes solutos que tanto podem agir na osmorregulação como na proteção de macromoléculas e biomembranas [13, 14]. Também foi observado correlação entre a época de coleta (relacionado à idade da planta) sobre estes solutos. No entanto, o TRA das folhas só se correlacionou positivamente com a prolina livre. 
Tabela 5: Matriz de Correlação de Pearson entre os tratamentos hídricos (TH), épocas de avaliação (EA), teor relativo de águas nas folhas (TRA), carboidratos solúveis totais foliar (CSTF), proteínas solúveis foliar (PSF), prolina livre foliar (PLR) e umidade do solo (US). Os valores destacados demonstram significância entre as variáveis.

\begin{tabular}{lrrrrrrr}
\hline & \multicolumn{1}{c}{ TRAT } & \multicolumn{1}{c}{ EP } & TRA & CSTF & PSF & PLF & US \\
\hline TRAT & 1 & & & & & & \\
EP & 0 & 1 & & & & & \\
TRA & 0,083679 & $-0,5328261$ & 1 & & & & \\
CSTF & $-0,0896284$ & 0,3266845 & $-0,39665945$ & 1 & & & \\
PSF & $-0,19228$ & $\mathbf{0 , 0 0 6 1 9 3}$ & $-0,14923342$ & 0,1126859 & 1 & & \\
PLF & $\mathbf{0 , 0 3 9 4 1 7}$ & $\mathbf{0 , 0 3 4 2 8 5}$ & $\mathbf{0 , 0 3 0 5 9 8 8}$ & $-0,1064143$ & 0,1760565 & 1 & \\
US & 0,2973037 & $-0,1621617$ & 0,16296449 & $-0,0802933$ & $\mathbf{- 0 , 0 1 3 1 8}$ & $\mathbf{- 0 , 0 1 2 8 1}$ & 1 \\
\hline
\end{tabular}

Considerando que a $C$. glaziovii é uma espécie adaptada à seca, a avaliação do índice de plasticidade (IP) fisiológica mostrou que as variáveis de maior plasticidade (Figura 4) foram às proteínas e prolina livre nas folhas, assim como prolina livre na raiz, todas com valores de IP acima de 0,7. No entanto, as outras variáveis como TRA, carboidratos na folha e proteína na raiz apresentaram uma IP inferior a 0,5, demonstrando pouca plasticidade. Esses resultados demonstram o caráter plástico da prolina, bem como sua importância na dinâmica metabólica da espécie, contribuindo, entre outros aspectos, para a sobrevivência e estabelecimento da C. glaziovii no ambiente natural. Embora o acúmulo de solutos orgânicos seja um processo dinâmico, que resulta de uma aclimatação rápida as condições do ambiente, seu papel na sobrevivência e manutenção da espécie no ambiente natural fica evidente.

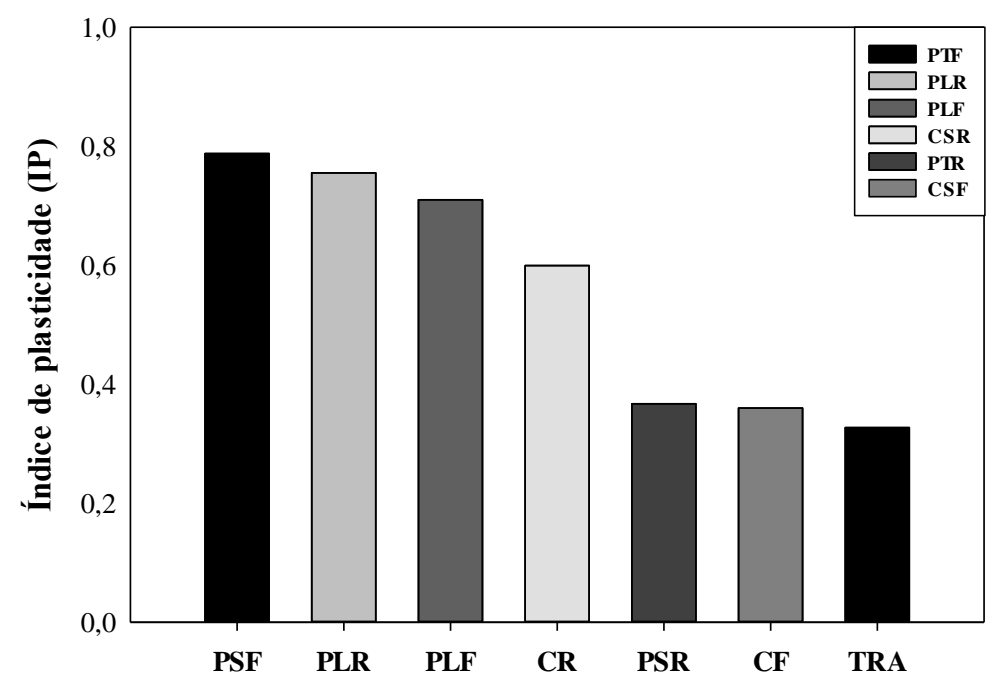

Figura 4: Índice de plasticidade (IP) dos parâmetros fisiológicos analisados em mudas de Ceiba glaziovii sob déficit hídrico por ciclos de suspensão de rega. Proteínas solúveis foliar (PSF), prolina livre radicular $(P L R)$, prolina livre foliar $(P L F)$, carboidratos solúveis totais radiculares $(C R)$, proteínas solúveis radiculares (PSR), carboidratos solúveis totais foliar $(C F)$ e teor relativo de água nas folhas (TRA).

Apesar do crescimento inicial das plantas ser um processo sensível a seca, os parâmetros avaliados permitem compreender alguns mecanismos utilizados pela espécie $C$. glaziovii para a sua sobrevivência, estabelecimento e manutenção nas florestas sazonalmente secas. A utilização destas informações pode contribuir para um melhor entendimento da dinâmica da espécie em seu ambiente natural, a melhoria das práticas de manejo e conservação da espécie, bem como a sua utilização em programas de reflorestamento de áreas degradadas. 


\section{CONCLUSÃO}

Os resultados do presente trabalho demonstram que a Ceiba glaziovii consegue manter valores adequados de água nos tecidos em situação de déficit hídrico intermitente, durante o período inicial do desenvolvimento. A prolina se acumula nas folhas e raízes em resposta ao déficit hídrico moderado, sugerindo um papel importante para a sobrevivência da espécie.

Os resultados também sugerem que, além do acúmulo de prolina, outros mecanismos fisiológicos, como a presença de mucilagem nas folhas, atuem na manutenção da turgescência foliar da $C$. glaziovii na fase de muda, abrindo espaço para futuros trabalhos com a espécie.

\section{AGRADECIMENTOS}

Os autores agradecem a Alyne Fontes Rodrigues de Melo pela concessão das sementes utilizadas na realização do presente trabalho e a UFS pela oportunidade de bolsa voluntária no Programa de Iniciação Científica (PICVOL/UFS).

\section{REFERÊNCIAS BIBLIOGRÁFICAS}

1. Allen $\mathrm{K}$ et al. Will seasonally dry tropical forests be sensitive or resistant to future changes in rainfall regimes? Environm Res Letters. 2017 Fev;12(2):001-023, doi.org/10.1088/1748-9326/aa5968

2. Marengo JA, Torres RR, Alves LM. Drought in Northeast Brazil - past, present, and future. Theor Appl Climatol. 2016 Ago;129(3):1189-1200, doi:10.1007/s00704-016-1840-8.

3. Silva EC, Albuquerque MB, Azevedo Neto AD, Silva Junior CD. Drought and Its Consequences to Plants - From Individual to Ecosystem. 2nd ed. São Cristóvão (Brasil): AKINCI, S. (Ed.); 2013. Chapter 2, Responses of Organisms to Water Stress; p. 17-47, doi.org/10.5772/53833.

4. Pires $\mathrm{CD}$ et al. A interferência das mudanças climáticas nas futuras produções agrícolas alimentícias de mato grosso do sul. $4^{\circ}$ Fórum Internacional Ecoinovar. 2015 Ago. Santa Maria/RS.

5. Taiz L. et al. Fisiologia vegetal. 7. ed., Artmed, 2017.

6. Farooq MA et al. Plant drought stress: effects, mechanisms and management. Agron Sustain. 2009 Mar; 29:185-212, doi.org/10.1051/agro:2008021.

7. Silva EC, Nogueira RJMC, Silva MA, Albuquerque MB. Drought stress and plant nutrition. Plant Stress 2011 Dez;5(Special Issue 1):32-41.

8. Gratani L. Plant Phenotypic Plasticity in Response to Environmental Factors. Adv Bot Hindawi Publ Corp. 2014 Abr;2014:17, doi.org/10.1155/2014/208747.

9. Paradizo IC et al. A plasticidade fenotípica como indicador de arbóreas não pioneiras mais tolerantes à elevada irradiância. Pesq Florest Bras. 2015 Dez;35(84):359, doi.org/10.4336/2015.pfb.35.84.927.

10. Freitas RS, Da Silva EC. Respostas fisiológicas de mudas de Aspidosperma pyrifollium (Apocynaceae) à ciclos de suspensão de rega. Sci Plena, 2018 Mai;14(5), doi.org/10.14808/sci.plena.2018.051201.

11. Fernandes TKS. Potencial ecológico e ambiental das espécies nativas do bioma caatinga do sertão central cearense. I Congresso Internacional da diversidade do semiárido. Dez 2016. Natal/RN.

12. Larcher W. Ecofisiologia Vegetal. São Carlos: RIMA; 2006.

13. Moura AR, Nogueira RJMC, Silva JAA, Lima TV. Water relations and organic solutes in young plants of Jatropha curcas L. under diferente water regimes. Ciênc Florest. 2016 Abr/Jun;26(2):345-354, doi.org/10.5902/1980509822735.

14. Strange K. Cellular volume homeostasis. Adv Physiol Educ. 2004 Dez;28:155-159, doi.org/10.1152/advan.00034.2004.

15. Silva PLK et al. Anatomia foliar de Ceiba glaziovii k. Schum. (Malvaceae-Bombacoideae), uma espécie medicinal da caatinga. I Congresso Internacional da diversidade do semiárido. 2016 Dec. Natal/RN.

16. Du Bocage AL, Sales MF. Família Bombacaceae Kunth no estado de Pernambuco, Brasil. Acta Bot Bras. 2002 Abr;16(2):123-139, doi.org/10.1590/S0102-33062002000200001.

17. Abrantes PM et al. Aviso de chuva e de seca na memória do povo: O caso do cariri paraibano. Rev Biol Farm. 2011;5(2):18-24.

18. Leal AJB. et al. Estudo fitoquímico antimicrobiano de Ceiba glaziovii Kuntze K. Schum. BIOFAR. Rev Biol Farm. 2001;5(1):75-76.

19. Lorenzi H. Árvores brasileiras: manual de identificação e cultivo de plantas arbóreas nativas do Brasil. Nova Odessa, São Paulo: Editora Plantarum. 2009; v.2. 229p.

20. Pereira Junior LR et al. Espécies da Caatinga como alternativa para o desenvolvimento de novos fitofármacos. Floresta Ambient. 2014 Dec:21(4):509-520, doi.org/10.1590/2179-8087.024212. 
21. Cairo PAE. Curso básico de relações hídricas de plantas. Vitória da Conquista: UESB; 1995.

22. Weatherley PE. Studies in the water relations of the cotton plant I: the field measurements of water deficits in leaves. New Phytologist. 1950 Mar;49(1):81-97, doi.org/10.1111/j.1469-8137. 1950.tb05146.x

23. Dubois $\mathrm{M}$ et al. Colorimetric method for determination of sugars and related substances. Anal Chem. 1956 Mar;28(3):350-356, doi.org/10.1021/ac60111a017

24. Bates LS, Waldren RP, Teare ID. Rapid determination of free proline for water-stress studies. Plant and soil. 1973 Ago;39(1):205-207, doi.org/10.1007/BF00018060

25. Bradford MM. A rapid and sensitive method for the quantitation of microgram quantities of protein utilizing the principle of protein-dye binding. Anal Bioch. 1976 Mai;72(1-2):248-254, .org/10.1006/abio.1976.9999

26. Valladares $\mathrm{F}$ et al. Shade tolerance, photo inhibition sensitivity and phenotypic plasticity of Ilex aquifolium in continental Mediterranean sites. Tree Physiol. 2005 Ago;25(8):1041-1052, doi.org/10.1093/treephys/25.8.1041

27. Mustafa HSB et al. Role of seed priming to enhance growth and development of crop plants against biotic and abiotic stresses. Bull Biol Allied Sci Res. 2017 Abr;2(2):1-11.

28. Silva EC, Silva MFA, Nogueira RJMC, Albuquerque MB. Growth evaluation and water relations of Erythrina velutina seedlings in response to drought stress. Braz J Plant Physiol. 2010 Dec;22(4):225-233, doi.org/10.1590/S1677-04202010000400002

29. Bray EA. Plant responses to water deficit. Trends Plant Sci. 1997 Fev;2(2):48-54, doi.org/10.1016/S13601385(97)82562-9

30. Valliyodan B, Nguyen HT. Understanding regulatory networks and engineering for enhanced drought tolerance in plants. Curr Opin Plant Biol. 2006 Fev;9:189-195, doi.org/10.1016/j.pbi.2006.01.019

31. Pimentel RR; Machado SR; Rocha JF. Estruturas secretoras de Pavonia alnifolia (Malvaceae), uma espécie ameaçada de extinção. Rodriguésia. 2011 Abril/Jun;62(2):253-262, doi.org/10.1590/21757860201162203

32. Da Silva EC et al. Aspectos ecofisiológicos de dez espécies em uma área de caatinga no município de Cabaceiras, Paraíba, Brasil. Iheringia. Série Botânica. 2004 Jul/Dez;59(2): 201-206.

33. Ayala CC et al. Respuestas fisiológicas y bioquímicas del fríjol caupí (Vigna unguiculata L. Walp.) bajo déficit hídrico. Rev Colombiana Ci Hortícolas. 2014 Jul/Dez;8(2):250-261, doi.org/10.17584/rcch.2014v8i2.3218

34. Rizzini CT. Cactáceas: os segredos da sobrevivência. Ciência hoje, Rio de Janeiro. 1987 Abr;5(30):3040.

35. Rocha JF, Pimentel RR, Machado SR. Mucilage-secreting structures of Hibiscus pernambucensis Arruda (Malvaceae): distribution, morphoanatomical and histochemical characterization. Acta Bot Brasil. 2011;25(4):751-763. http://dx.doi.org/10.1590/S0102-33062011000400003

36. Franceschi VR, Horner Jr HT. Calcium oxalate crystals in plants. Bot Rev. 1980;46:361-427, doi:10.1007/BF02860532

37. Magalhães ACTV, Almeida JG. O uso da mucilagem de cacto em pastas de gesso: efeitos na absorção de água e na resistência à flexão estática. [dissertação] 2009. 22-121 p.

38. Sáenz C, Sepúlveda E, Matsuhirob B. Opuntia spp mucilage's: a functional componente with industrial perspectives. J Arid Environm. 2004;57:275-290, doi:10.1016/S0140-1963(03)00106-X. 